\title{
Environmental System Modeling and Landscape Management
}

\author{
Rodrigo Affonso de Albuquerque Nóbrega ${ }^{a}$ \\ Fernanda Zimmermann Teixeirab \\ Doris Aleida Villamizar Sayagoc \\ ${ }^{a}$ Assistant Professor, Graduate Program on Analysis and Modeling of Environmental Systems, Federal \\ University of Minas Gerais, Belo Horizonte, MG, Brazil. \\ E-mail: raanobrega@ufmg.br \\ ${ }^{b}$ Associate Research, Group of Road and Railroad Ecology, Graduate Program on Ecology Federal \\ University of Rio Grande do Sul, Porto Alegre, RS, Brazil. \\ E-mail: fernandazteixeira@gmail.com
}

'Full Professor, Center for Sustainable Development, University of Brasilia, Brasília, DF, Brazil E-mail: doris.sayago@gmail.com

doi:10.18472/SustDeb.v11n2.2020.33466

The rising pressure over the environment, associated with the increase in the demand for natural resources, resulted in an increased attention to social and environmental issues. However, the 21st century reveals many key challenges to reach a sustainable landscape management. The understanding that environmental systems are a result of complex interactions among multiple variables resulted in the need to develop and apply more robust analyses to generate knowledge about the environment. Moreover, the increased attention to environmental issues also created an important demand for predicting future scenarios to support current decision making related to landscape management.

The use of specialized tools and methods for modeling environmental systems strengthens the human capacity to intervene on behalf of landscape management for a sustainable environment. Environmental modeling, due to its interdisciplinary nature, has been widely applied in understanding the causal mechanisms between environmental systems and their interactions with different socioeconomic contexts in Brazil and worldwide. The current technological stage allows not only the use of sophisticated geospatial tools but also to develop and explore transdisciplinary models to help the understanding of the complex interactions between humans and nature.

The GIS have reached relative maturity in terms of analytical capacity and functionality. Their current emphasis shifted towards the construction of sophisticated models for representation of environmental systems and time-space computational simulations. Environmental geographic modeling seeks to understand the dynamics of spatial phenomena (which have a geographic expression), whether natural or anthropic as well as their role in the organization and evolution of Earth's systems.

It consists of a theoretical-instrumental procedure that involves a set of quantitative and spatial techniques, aiming to operationalize a systemic approach. As a result, the integrated development of Earth sciences (Geology, Geography, Ecology, Climatology, among others) opens up a wide field for investigating environmental processes, which currently is considered as a cutting-edge research topic and a thematic priority. 
In the seek for sustainable development, the modeling of environmental systems is gaining an outstanding role to create integrated knowledge of the environment, the society, and their interactions. It provides methodologies, technologies, and products capable of subsidizing and driving public policies for the prevention and mitigation of human impacts, especially concerning global changes. Thus, the environmental sciences have been trying to insert the environmental modeling into the designing processes of public policies and the evaluation of their performance. This has been the premise of the Graduate Program in Analysis and Modeling of Environmental Systems (AMSA) at UFMG, and it has propelled the program's research areas of Environmental Analysis, Systems Modeling, and Landscape Management.

The research approach traditionally practiced by AMSA is quantitative, which somewhat restricts the scope and impact in society, including the scientific peers in the CAPES' environmental sciences group. Early in 2018, through a wise and opportune approach, the Center for Sustainable Development (CDS) at UnB invited AMSA to start an academic partnership between the two programs. The CDS envisioned that quantitative geographic modeling could enhance the high quality of the research practiced in the house, traditionally in the qualitative domain. For AMSA, the opportunity of partnership with a mature graduate program, recognized for its excellence, was great to reinforce its growing and strengthening process.

The partnership was implemented by the end of 2018 with the III Symposium on Systems Modeling and Landscape Analysis of the Graduate Program in Analysis and Modeling of Environmental Systems, which is a biannual event of AMSA that, in this edition counted with the co-participation of the coordination CDS and associated researchers. This event aimed to present and debate the challenges and perspectives of environmental systems modeling, to discuss the methods and applications of geographic modeling and landscape management, and to address the role of environmental modeling in the formulation of policies for landscape planning and management.

The Symposium has become a platform for the convergence of scientific articles and the basis for the preparation of this Dossier. In addition to selected manuscripts from the event, the Dossier "Modeling Environmental Systems and Landscape Management" of the Sustainability on Debate journal also gathers scientific manuscripts that address topics related to innovative methodologies in quantitative modeling and GIS capable of promoting ways to improve management and territorial governance in for socio-environmental sustainability.

The Dossier includes 9 articles. The first one, entitled "Agriculture and sustainable landscapes: agricultural diversification in the state of Minas Gerais", analyzes the dynamics of agriculture production and the diversity of its products from the environmental sustainability standpoint. The findings show that the agricultural diversity in the municipalities are associated with family farming context.

The second article, "Non-Timber Forest Products in the Brazilian Amazon and Cerrado biomes: MultiScale Governance for Implementing Enhanced Socio-biodiversity Chains" contextualizes non-timber forest products as a channel to drive policies for social and biodiversity governance in their production chains in the two most extensive biomes Brazilians.

The article "The Handwriting of society on the landscape: modeling of the environmental changes on the borders of protected areas located in the Espinhaço Mountain Range (state of Minas Gerais, Brazil)" investigates the patterns of natural resources use by the local population and the respective dynamics of land use over time in the context of the creation of two protected areas in a sensitive region.

In the article "Simulated deforestation versus satellite data in Roraima, northern Amazonia", the authors analyze the pattern of land cover and land-use change, with special regards to the deforestation phenomena. They simulated scenarios for the period 2011-2017 and compared the results of their computational approach to the PRODES official data. The study investigated areas of silvopastoral use and excluded indigenous lands and conservation units, which together concentrate most of the state's territory. 
Next, in the work "Use of multicriteria analysis to define priority areas for reforestation in the Piranga River Basin/MG", the authors analyze and identify areas that could be designated for reforestation. The investigation took the perspective of the areas of permanent preservation consolidated in the new Forest Code and multicriteria geographic analysis techniques to support decision-making. The study focused on an environmentally sensitive and water-recharge region located within the geographic context of the environmental tragedy driven by the dam break in Mariana/MG.

The sixth article in the Dossier, "Geotechnologies as an environmental licensing support tool in the state of Piaui", presents and discusses the use of tools and open access geographic data in the environmental licensing process. Also in this theme of open access data, the article "The application of remote sensing techniques using MODIS (MCD45A1) images to burned areas identification and assessment in the metropolitan region of Belo Horizonte - Minas Gerais, Brazil" analyzes the use of open access orbital images and traditional techniques for recognizing and extracting features in the images, especially for burned areas susceptible to environmental damage in the peri-urban context.

In the eighth article, "Case study of a model of local solar radiation potential and discussion on the associated sustainable applications and potentials", the authors present a detailed investigation focused on mapping and quantifying the potential for solar energy generation in densely-built areas. The study used technologies such as drone imaging to capture both the level of detail and the geometry aspects of the complex roof surfaces in urbanized areas.

Finally, the article "Dry port location optimization to foster sustainable regional development" presents a geographically explicit model for mapping and identifying regions with the greatest feasibility for implementing dry ports in the state of Minas Gerais. Other than the traditional location-allocation optimizing approach practiced by engineering, the model adds multicriteria analysis of the continuous surface variables including socioeconomic characteristics such as the generation of jobs and local revenue, together with environmental elements.

Although the III Symposium on Environmental Modeling and Landscape Management occurred in the end of 2018, a month before the inauguration of Bolsonaro's administration, and the present Dossier is being published in August 2020 (Annus Horribilis, in reference to the Editorial of volume 11 of the Sustainability on Debate), the material presented in this Dossier exposes a critical vision of the academy, so massacred in this same period, about environmental issues of common interest and benefit to society. The environment, literally inflamed in 2019 and in the present Annus Horribilis, calls for better days. Thus, the academy is trying to make a difference.

We appreciate the colleagues who attended the event, the authors who sent the manuscripts, and the reviewers who collaborated with this edition of the Dossier. Good reading.

Editors of the Dossier 